\title{
Behavioral Economics and the Environment
}

\author{
Gardner Brown • Daniel A. Hagen
}

Accepted: 24 February 2010 / Published online: 20 April 2010

(C) Springer Science+Business Media B.V. 2010

Many economists have embraced a paradigm characterized by perfect information, rational expectations and an otherwise benign environment in which perfect competition reigns, with very minor asides for imperfect competition. Rumblings of opposition have been growing louder. Nobel prizes are being awarded to scholars who have taken us out of this historic straight jacket. Lo and behold there can be asymmetric information, increasing returns to scale, cooperative behavior and agents who consistently fail to optimize.

Behavioral economics is another theme gathering strength, and it may be particularly germane to environmental and resource economics. Consumer theory, measurement of benefits, intergenerational discounting, mechanism design, and the role of fairness are all subjects of importance for environmental and resource economics and they are all areas in which behavioral economics may provide important insights. To explore this possibility we brought together a group of distinguished scholars for a workshop hosted by Western Washington University. This special edition presents a collection of papers from that workshop. We have included a diversity of perspectives, ranging from the skeptical to the supportive. While not intended as a comprehensive survey of the field, these papers provide a general sense of the scope of current research.

There is growing evidence that fairness is an argument in an individual's utility function. If we believe that consumer sovereignty counts, why would utility derived from perceived fairness count less than the same amount derived from any other argument in the utility function? That is the principle subject of Johansson-Stenman's and Konow's (2010) "Fair air: distributive justice and environmental economics." We encourage you to read this contribution with an open mind. The paper covers an enormous amount of ground. We must touch down only selectivity. Fairness is a fact of life. In the "ultimatum game", when one is given a lump sum (say, \$20) only if his/her offer of an amount to another participant is accepted, there

\footnotetext{
G. Brown $(\varangle)$

Professor Emeritus of Economics, University of Washington, University Fellow,

Resources for the Future, Seattle, WA, USA

e-mail: gbrown@u.washington.edu

D. A. Hagen

Department of Economics, Western Washington University, Bellingham, WA, 98225-9074 USA
} 
is no evidence from hundreds of experiments that the equivalent of $\$ .01$ is ever accepted, contrary to traditional maximizing principles of economics. It seems reasonable to invite alternative story lines.

Johansson-Stenman and Konow suggest that fairness is rarely included in economic models because it is believed that there is too much subjectivity, there is too much self serving, and because it seems intractable. Not true they say. Put simply, the benefit of including fairness in analysis outweighs the complexity costs of including it. For example, including fairness in analysis will have greater predictive power and will have strong practical relevance in a policy environment where fairness matters. This is a theme that they demonstrate throughout the paper.

Four elements characterize distributive preferences: accountability, efficiency, need and equality. The paper's treatment of these elements is extensive. Consider a couple of examples. The "equality" element refers to a moral rule used in some personal settings, as when a dining bill is shared or in the ultimatum game when approximately equal shares often are observed. The "accountability" element bears on how benefits or burdens should be distributed, and integrates proportionality and responsibility. An example provided by the authors shows that polluters should pay proportionally to the total level of emissions. Such results may be incompatible with pollution rights distributed in proportion to historical emissions. One wonders if those surveyed were admonished to consider political feasibility. Nevertheless, following the accountability principle, it could be argued that each person in the world should have equal initial rights to pollute and a market could be created to allow trade to improve efficiency.

While efficiency is a natural concern, the authors point out the many studies documenting subjects willing to make themselves worse off in order to increase the total size of the pie or to punish other players who are perceived to have behaved unfairly or uncooperatively. There also is experimental evidence that participants are willing to trade off efficiency and accountability in order to benefit people in need.

Johansson-Stenman and Konow argue persuasively that fairness concerns will play a role in environmental policy formation. Firms and governments may not have direct positive concerns about the environment but their constituents and workers do and behave accordingly. As a possible example, major corporations such as Apple, Nike, Pacific Gas and Electric, Exelon and PNM Resources have resigned from the U.S. Chamber of Commerce because of its opposition to policies designed to combat global climate change. Researchers have learned that respondents in stated preference surveys have to be assured that polluting miscreants also will have to pay, otherwise the respondents balk at the unfairness of it all. After considering these and many other issues, the authors conclude that that the incorporation of fairness into environmental economics is fertile ground for future work.

Carlsson (2010) discusses the implications of behavioral economics for stated preference surveys. He considers four areas: incoherent preferences, learning and constructed preferences, context dependence, and hypothetical bias. In each case he examines the principal findings within the literature and considers ways in which these findings can be used to improve the reliability of stated preference studies. He also suggests that stated preference methods may help us to improve our understanding of behavioral economics.

Carlsson begins by reviewing the distinction between revealed preferences and normative preferences. Preferences revealed through choices may be inconsistent with normative preferences (which reflect their actual interests). One possible explanation is limited personal experience, suggesting that an antidote may be to examine the difference between experienced and inexperienced respondents. This is complicated by the fact that the decision to obtain experience is endogenous in many cases. Under some circumstances experience is not 
endogenous (such as experiencing a major power outage), and in at least one such case there is evidence that experience can affect preferences.

Incoherent preferences may also take the form of a divergence between Kahneman's "decision utility" (as anticipated at the time the decision is made) and "experienced utility" (as realized at the time of consumption). The former is studied with stated preference surveys, but the latter is of greater relevance for welfare economics. Carlsson considers the use of well-being studies, which have the potential to provide estimates based on experienced utility.

Carlsson then turns to the issue of learning and constructed preferences. In many contexts-including markets, experiments, and surveys - stable preferences may emerge only after a period of learning. This suggests that it may be useful to adopt study designs where respondents make repeated choices.

Context dependence is inherent to stated preference studies. Is sensitivity to context greater for hypothetical payments than for actual payments? Carlsson discusses a natural field experiment in which some respondents made actual payments and others stated hypothetical payments, where the degree of anonymity, and information provided about the contributions of others were varied. The context was shown to affect contributions to roughly the same extent for both hypothetical and actual payments. Some evidence suggests that the problem may be no more serious for stated preference studies than for revealed preference studies, although the issue has not yet been resolved.

Finally, Carlsson examines the issue of hypothetical bias in greater depth. Laboratory experiments involving actual transactions have been used to test for hypothetical bias by comparing results to those obtained from stated preference surveys with hypothetical payments. Carlsson reviews the literature, and concludes that the findings are mixed. He discusses evidence from both stated preference surveys and laboratory experiments which suggests that the divergence between stated preference predictions and actual purchases is not due to hypothetical bias alone. Other studies comparing these approaches are also reviewed, with Carlsson concluding that lab experiments seem to do somewhat better at predicting field behavior than stated preference surveys (although once again the results are mixed).

Divergent behavior between the lab and the real world - and between surveys and the real world - may be due to a number of factors, including choice-set restriction. In both the lab and in a survey the choice sets are clearly delineated. In the real world the context may seem broader and less clear. Differences can be mitigated with survey protocols such as reminding respondents of budget constraints, or via the "time-to-think" protocol, where a respondent is visited, presented with information and responds the following day.

As Carlsson points out, it is very difficult to test for effects such as hypothetical bias to the extent that other factors are also present and influence the responses. Hypothetical bias is an issue for which practitioners of stated preference surveys can learn from behavioral economists. The literature on stated preference surveys can also help to inform behavioral economists, as the method can be used to explore many issues of common interest.

Knetsch (2010) was among the first economists to venture into the realm of behavioral economics and his contributions remain among the most important. In his contribution to this volume he provides an overview of research on the values of gains and losses, and discusses the implications for environmental valuation. As Knetsch points out, observations of large disparities between the values of gains and losses are widespread. The existence and magnitude of a reference (or endowment) effect has been found to vary with the context. In some cases it may be absent, and in some cases its presence may be due to inexperienced participants or to the nature of the experimental procedure. Knetsch argues, however, that these factors are unlikely to explain many of the observed disparities. Citing recent research, 
Knetsch argues that the participants' valuations are based on their reference states. While this can be altered in the study design, the fact that the reference state matters has important implications for environmental valuation.

Knetsch begins by reviewing empirical findings regarding disparities between the values of gains and losses. This literature stretches back to a 1974 study that found disparities among duck hunters in their valuation of gains versus losses of breeding habitat. Numerous controlled laboratory experiments conducted by Knetsch and others also found disparities to be commonplace. Natural experiments have produced results consistent with the laboratory findings. For example, a study of the price elasticity of demand for eggs found a discrepancy between "gains" (a price decrease) and "losses" (a price increase), the elasticity being higher in the latter case, suggesting greater sensitivity to losses. Evidence of disparities also comes from studies of the stock market, housing markets, labor markets, and the market for auto insurance.

After reviewing the literature showing valuation disparities, Knetsch then considers counterexamples. In some cases no endowment effect would be expected. For example, a merchant who is holding items in inventory for sale would not feel a sense of loss as an item is sold from inventory. Repetitive market transactions are another example where exceptions to the disparity have been observed. Studies using repeated trials with a second price Vickrey auction have demonstrated convergence of buy and sell prices. However other studies show that the use of a ninth price auction causes the endowment effect to re-emerge. This suggests that the use of repetitive market exchange does not consistently eliminate valuation disparities.

Some studies suggest that experienced traders have exhibit smaller valuation disparities than inexperienced traders. Knetsch argues that it may not be differences in experience that is driving the results, but rather differences in reference states. Frequent traders expect to trade and would feel a loss if they fail to trade, whereas the non-traders may be reluctant to give up their initial endowment. This difference in reference states could explain the observed results.

Recent studies suggest that experimental procedures used in studies showing endowment effects may be responsible for the observed disparities in values. Specifically, it has been suggested that the experimental designs have created incentives for participants to keep the initial endowments, leading to an observed endowment effect. When these experiments are redesigned to remove these incentives, the endowment effect disappears. Knetsch argues that the experimental controls necessary to eliminate the valuation disparities have the effect of changing the participants' reference states. It may be these changes in reference states that are responsible for the observed results, rather than the procedural controls themselves. Recent empirical tests provide support for this interpretation.

Knetsch then turns to a discussion of the implications of valuation disparities for environmental valuation. He argues that in many contexts, WTA should be used instead of WTP when valuing resources. For example, when valuing the loss of duck habitat, WTP would be the appropriate value only if people's reference states are absent the duck habitat in question. If that is not the case, then the use of WTP will substantially undervalue the resource. As Knetsch argues, the choice of value is not as simple as examining legal entitlements. Rather, the reference state may depend on what the community regards as "the normal or expected state", "legitimate expectations", "psychological ownership", or "endogenously determined probabilistic expectations".

Given the importance of the reference state, the use of measures based on WTP may in some cases result in substantial undervaluation of environmental resources. Knetsch is critical of the economics profession for largely ignoring this issue in benefit-cost analysis, natural resource damage assessment, and the design of environmental policies. 
Hepburn, Duncan and Papachristodoulou (2010) cite Samuelson (1937) as the creator of the exponential discounted utility model which has prevailed for well more than half a century. Cracks in this convention have occurred and are widening as both theoretical and empirical evidence support hyperbolic discounting, here meaning a time-declining discount rate. Hepburn et al. discuss this development relying heavily on the controversy set off by the Stern report (2007) about global climate change which used a discount rate of $1.4 \%$. Introducing uncertainty in the growth model, as Weitzman $(1998,2001)$ does, results in a declining discount rate as does, in effect, an assumption that the value of natural resource intensive goods/services grows relatively more scarce (Sterner and Persson 2008).

Hyperbolic discounting can explain observed preference reversals (today $a>b$, in the future $b>a$ ). The authors summarize alternative explanations as well as criticize the empirical studies and conclude that empirical support for hyperbolic discounting by individuals is "robust," including evidence from neural studies.

The authors then turn to policy implications and conclude that while hyperbolic discounting may account for some human and animal behavior, its use in benefit/cost analysis is less convincing. What are researchers to do if people appear to make inferior choices? Citing literature, the authors report (1) revise the objective function; (2) change the measure of well-being; (3) make welfare a direct function of choice or (4) opportunities. Hepburn et al. then summarize "libertarian paternalism" which involves the government creating a "choice architecture" which nudges people to choose better (e.g., save more), increase the rate of organ donation, exhibit better self control, or eat more healthily because of rearranging food in school cafeterias.

Hepburn, et al. conclude by demonstrating the consequences of a hyperbolic discount rate in a fishery model with a minimum viable population and a concave utility function in harvest. One planner finds the optimal path and sticks to it, increasing the optimal stock as the discount rate falls. An alternative planner revisits the optimization problem over time, repeatedly starting anew. The consequence of this behavioral pattern in the simulation is that the fishery collapses because at the point of a minimum viable population the fish marginal rate of return is lower than the relatively high early on discount rate. The authors suggest that this story might reflect the history of the Canadian cod and the Peruvian anchoveta fishery.

In "Strategic use of Information", Asheim (2010) examines the promotion of intrinsic moral motivation as an alternative to conventional economic instruments. Asheim's central point is that environmental agencies may behave strategically in their use of information when seeking to promote intrinsic motivation. To examine the likelihood and consequences of such behavior, Asheim develops a model in which individuals are motivated by moral considerations, and information is available asymmetrically to the environmental agency and the individuals whose behavior they seek to influence.

In Asheim's setting, contributions to environmental protection are voluntary. The individual's contribution affects utility both through its (negative) effect on private consumption and through the inclusion of moral motivation in the utility function. Individual utility depends on private consumption, total provision of the public good, and the disutility associated with "shirking", which is measured in terms of deviations of the individual's contribution from the socially optimal contribution (as perceived by the individual). From the individual's perspective, the optimal contribution thus depends in part on the assessment of the socially optimal contribution, which in turn depends on the available information. The standard results obtain. When possessing full information, the individual's contribution will be less than the socially optimal contribution and the public good is underprovided. The moral motivation leads to a larger contribution than would occur in its absence, but it is insufficient to provide optimal provision of the public good. 
In this setting, the environmental agency receives information about the state of the environment and must decide whether to release it. Individuals are aware that the agency may behave strategically. The agency is aware of the impact of its decision on the contributions of individuals. Consider the case where a signal is received by the agency indicating a low level of threat to the environment. It may decide to withhold the signal so as to avoid further depressing the contributions of individuals (which tend to be below the socially optimal contribution). In this case the signal would not be received by the individuals. They would understand, however, that the absence of a signal from the agency does not imply that the agency has not received a signal. Indeed, in equilibrium the individuals would assess (correctly) that the signal would be withheld if received, and they would adjust their behavior accordingly. The agency, lacking a means for ensuring credibility, must take this into account, the result being that they have an incentive to withhold the information (as expected). This results in an equilibrium in which the agency is strategically withholding information.

The equilibrium described above is neither first-best nor second-best. A second-best equilibrium could be obtained if the agency had some means to ensure its credibility so as to prevent individuals from "discounting" the significance of an absent signal. Drawing from the literature on monetary policy, Asheim suggests that independence of the environmental agency - in the manner of an independent central bank-may help to ensure its credibility. Asheim points out, however, that the distortion associated with insufficient moral motivation would remain. In other words, even with a perfectly credible agency providing full information, individuals will tend to contribute less than the socially optimal amount. On the other hand, if the environmental agency is directed to use conventional economic instruments (such as Pigovian taxes), then the benevolent agency has an incentive to use all information and the optimal effort can be induced in each state. Viewed in this way, attempts to promote intrinsic moral motivation are a poor substitute for optimal economic instruments. Information regarding environmental threats may have implications for the political feasibility of optimal economic instruments. Asheim briefly mentions this point, without developing it. As noted by a reviewer, strategic use of information to gain support for public policy may be more important than the case considered by Asheim. Many of the same principles are likely to apply regarding the importance of credibility and the means for helping to ensure it.

Smith and Moore (2010) consider the implications of behavioral economics for benefit-cost analysis. Behavioral economics seems to have identified instances of "incoherent preferences", where incoherence refers to behavior uncharacteristic of traditional Homo economicus. A ready example of incoherent preferences occurs when there is context dependence. What I specifically purchase depends on how products are arranged on the shelves or whether the manager of a cafeteria puts sweets or fruits early on in the line because the "early bird catches the worm." How should benefit-cost analysis be modified to accommodate incoherent preferences?

Kerry Smith and Eric Moore are concerned primarily with what they view as a discrepancy between how analysts such as Sugden (2009) or Bernheim and Rangel (2007, 2009) address this question and how real world $\mathrm{B} / \mathrm{C}$ analysis is done. The root problem is that $\mathrm{B} / \mathrm{C}$ analysis usually is conducted in instances where the objects of choice cannot readily be repeatedly purchased, a condition some analytical behavioral revisionists require.

One way to reduce incoherent preferences is to add conditions ancillary to prices and income constraints into the model to account for the variable timing or framing of the decision context. On the one hand, this is a natural strategy to finesse otherwise incompatible observations. Smith and Moore in a suggestive formal model introduce limits on cognitive capacity, decision making energy and physical dexterity to illustrate this point. On the other hand, since so much of applied B/C analysis relies on data that are historically time and 
place specific, transmogrifying the historical price, income and ancillary conditions to fit the project environment at hand seems daunting.

Smith and Moore end their study by reporting on an experiment in which they constrain some participants' behavior in some of the treatments and not for others. The results indicate that market performance was affected by introducing "non-traditional" buyers. This reportedly is a preliminary analysis and one can look forward to how the authors package it into applied B/C analysis with behavioral coloration.

Brown and Hagen (2010) begin with a provocative introduction in which they put forth the idea that "all economics is behavioral." Narrowing the "all," they argue that those who do non-market valuation have always been concerned about the behavioral biases seemingly involved in stated preference studies. The authors then sketch out the many ways the neoclassical paradigm has been attacked by behavioral fusillades with many appropriate references for the interested reader to pursue. The authors construct an invitational intellectual matrix where the columns are "Rationality Choice Theory"; "Bounded Rationality", meaning loss aversion, framing, endowment effects; "Bounded Self-interest", meaning altruism and fairness; and "Bounded Willpower", meaning limited self control. The rows include "What has failed?" "Can we control?", and "What is at risk and when?". Each of the twenty one boxes presents a challenge and opportunity for the interested researcher to tackle. For example, under bounded rationality, Jack Knetsch's contribution to this collection of papers discusses the endowment effect.

Shogren, et al. choose an experiment to contribute to the box, Context-dependence Preferences and Endowment Effect under Bounded Rationality. To test the extent of the endowment effect, the authors conduct a Vickrey auction where participants know the resale value of the good in question should they win the auction. Subjects can lose either by bidding too much or by bidding too little (i.e., less than their resale value). The results suggest that subjects treat the two types of cost differently and the predicted signs to corroborate the endowment effect are not observed. An alternative explanation for the observed behavior is postulated. These results, the authors propose, suggests that the endowment effect is not a universal phenomenon.

Second, they design a theoretical model to shed light on Mechanism Design and Bounded Self-interest. In it the effect of a regulator's subsidy interacts negatively with social motives a firm concerned about reputation might have. In a model where firms have a distribution of social motives and behave strategically, they conclude that the socially oriented firms are subsidized less than optimum while the selfish firms expend optimal effort.

Acknowledgements The authors thank Wilder Construction and the College of Business and Economics at Western Washington University for their generous support of the workshop at which these papers were presented.

\section{References}

Asheim GB (2010) Strategic use of environmental information. Environ Resour Econo. doi:10.1007/ s10640-010-9353-x

Bernheim BD, Rangel A (2007) Toward choice theoretic foundations for behavioral welfare economics. Am Econ Rev, Pap Proc 97:464-470

Bernheim BD, Rangel A (2009) Beyond revealed preference: choice theoretic foundations for behavioral welfare economics. Q J Econ 124: 51-104

Brown G, Hagen DA (2010) Behavioral economics and the environment. Environ Resour Econ doi:10.1007/ s10640-010-9357-6 
Carlsson F (2010) Design of stated preference surveys: is there more to learn from behavioral economics? Environ Resour Econ. doi:10.1007/s10640-010-9359-4

Hepburn C, Duncan S, Papachristodoulou A (2010) Behavioural economics, hyperbolic discounting and environmental policy. Environ Resour Econ doi:10.1007/s10640-010-9354-9

Johansson-Stenman O, Konow J (2010) Fair air: distributive justice and environmental economics. Environ Resour Econ doi:10.1007/s10640-010-9356-7

Knetsch JL (2010) Values of gains and losses: reference states and choice of measure. Environ Resour Econ doi:10.1007/s10640-010-9355-8

Samuelson PA (1937) A note on the measurement of utility. Rev Eco Stud 4:155-161

Smith VK, Moore EM (2010) Behavioral economics and benefit cost analysis doi:10.1007/s10640-010-9358-5

Stern N (2007) The economics of climate change: the stern review. Cambridge University Press, London

Sterner T, Persson UM (2008) An even sterner review: introducing relative prices into the discounting debate. Rev Environ Econ Policy 2: 61-76

Sugden R (2009) Market simulation and the provision of public goods: a non-paternalistic response to anomalies in environmental evaluation. J Environ Econ Manag 57:87-103

Weitzman ML (1998) Why the far distant future should be discounted at its lowest possible rate. J Environ Econ Manag 36:201-208

Weitzman ML (2001) Gamma discounting. Am Econ Rev 9:261-271 